\title{
Personality Disorders in General Medical Conditions
}

\section{Faruk Uguz*}

Psychiatry, Selcuk University, Meram Faculty of Medicine, Konya, Turkey

The Diagnostic and Statistical Manual of Mental Disorders, Fourth Edition (DSM-IV) defines personality disorder as an 'enduring pattern of inner experience and behavior that derviates markedly from the expectations of the individual's culture', which are manifested in two or more of the following areas: cognition, affectivity, interpersonal functioning and impulsive controls [1]. DSM-IV also defines personality traits as 'enduring patterns of perceiving, relating to, and thinking about oneself and the environment', which are not necessarily a diagnosis of disorder [1,2].

Half of the patients with personality disorders also have any comorbid Axis I psychiatric diagnosis. Personality characteristics may affect the response to treatment of all Axis I psychopathologies and may increase personal incapacitation, morbidity and mortality in these subjects [2]. A recent meta-analysis has suggested that depression comorbid with a personality disorder has double the odds ratio of a poor outcome compared to those with no personality disorder [3]. Previous studies have shown that patients with personality disorders seen at psychiatric outpatient clinic have more reduced quality of life (QoL) levels compared to age-and gender-adjusted normal data [4]. Moreover, it has been reported that personality disorders are associated with poorer treatment outcomes of obsessive-compulsive disorder [5].

There is growing interest in the relationship between general medical conditions and personality traits or disorders. However, the studies are mostly based on scales assessing personality traits rather than structured clinical interview diagnosing personality disorders. Patients with several medical illnesses such as fibromyalgia, chronic urticaria, systemic lupus erythemtosus, and asthma have approximately 3 -fold higher prevalence rate of personality disorders, especially types of obsessive-compulsive and avoidant [6-9]. Similar to Axis I psychiatric disturbances, personality disorders can negatively affect QoL in patients with medical illnesses. In a community sample, it has been reported that personality disorders appears to be more important predictors of QoL than somatic health and Axis I disorders [10]. Personality dsorders were found to be associated with poor QoL in asthma patients. In addition, a cross-sectional study in patients with chronic urticaria suggess that personality disorders can affect QoL as negatively as Axis I disorders [11]. On the other hand, data on the effects of personality disorders on prognosis of medical diseases are very inadequate, although there are some studies with respect to personality traits [12].
In conclusion, personality disorders are not only frequently in patietnts with general medical condition, but may also affect QoL and potentially the prognosis in these patients.

\section{References}

1. Strawbridge WJ, Deleger S, Roberts RE, Kaplan GA (2002) Physical activity reduces the risk of subsequent depression for older adults. Am J Epidemiol 156: 328-334.

2. Cloninger CR, Svrakic DM (2000) Personalitydisorders. Kaplan \& Sadock's Comprehensive Textbook of Psychiatry (7thedn). Lippincott Williams \& Wikins Philadelphia.

3. Newton-Howes G, Tyrer P, Johnson T, Mulder R, Kool S, et al. (2013) Influence of Personality on the Outcome of Treatment in Depression: Systematic Review and Meta-Analysis. J Pers Disord.

4. Narud K, Mykletun A, Dahl AA (2005) Quality of life in pateints with personality disorders seen at an ordinary psychiatric outpatient clinic. BMC Psychiatry 5: 10.

5. Thiel N, Hertenstein E, Nissen C, Herbst N, Külz AK, et al. (2013) The effect of personality disorders on treatment outcomes in patients with obsessivecompulsive disorders. J Pers Disord 27: 697-715.

6. Uguz F, Engin B, Yilmaz E (2008) Axis I and Axis II diagnoses in patients with chronic idiopathic urticaria. J Psychosom Res 64: 225-229.

7. Uguz F, Kucuk A, Cicek E, Kayhan F, Tunc R (2013) Mood, anxiety and personality disorders in patients with systemic lupus erythematosus. Compr Psychiatry 54: 341-345.

8. Uguz F, Ciçek E, Salli A, Karahan AY, Albayrak I, et al. (2010) Axis I and Axis II psychiatric disorders in patients with fibromyalgia. Gen Hosp Psychiatry 32: 105-107.

9. YÄ \pm Imaz A, Cumurcu BE, Etikan I, Hasbek E, Doruk S (2014) The effect of personality disorders on asthma severity and quality of life. Iran J Allergy Asthma Immunol 13: 47-54.

10. Moreno-Jiménez B, López Blanco B, Rodríguez-Muñoz A, Garrosa Hernández $E$ (2007) The influence of personality factors on health-related quality of life of patients with inflammatory bowel disease. J Psychosom Res 62: 39-46.

11. Uguz F, Engin B, Yilmaz E (2008) Quality of life in patients with chronic idiopathic urticaria: the impact of Axis I and Axis II psychiatric disorders. Gen Hosp Psychiatry 30: 453-457.

12. Jokela M, Pulkki-Raback L, Elovainio M, Kivimaki M (2013) Personality traits as risk factors for stroke and coronary heart disease mortality: pooled analysis of three cohort study. J Behav Med.
${ }^{*}$ Corresponding author: Faruk Uguz, Psychiatry, Selcuk University, Meram Faculty of Medicine, Konya, Turkey, E-mail: farukuguz@gmail.com

Received January 20, 2014; Accepted January 24, 2014; Published January 26 , 2014

Citation: Uguz F (2014) Personality Disorders in General Medical Conditıons. J Clin Case Rep 4: e129. doi:10.4172/2165-7920.1000e129

Copyright: (c) 2014 Uguz F. This is an open-access article distributed under the terms of the Creative Commons Attribution License, which permits unrestricted use, distribution, and reproduction in any medium, provided the original author and source are credited. 